\title{
Predicting Job Stress and Job Satisfaction among Registry Staff of Takoradi Technical University in Ghana: A Discriminant Analysis Approach
}

\author{
Mr. Michael Bosomtwe ${ }^{1}$ \\ Institute of Distance and e-Learning, Education Department, \\ University of Education, Ghana \\ 00233-244096657 Email:bosomtwemichael@gmail.com
}

Ms. Vera Serwa Nkrumah ${ }^{2}$

Department of Civil Engineering, Takoradi Technical University, Takoradi, Ghana. 00233-208156792 Email: vera.nkrumah@ttu.edu.gh/vera.nkrumah@tpoly.edu.gh

Mr. Francis Joe Ankumah ${ }^{3}$

Office of the Vice Chancellor, Takoradi Technical University, Takoradi, Ghana. 00233-24288136Email: francis.ankumah@ttu.edu.gh/francis.ankumah@tpoly.edu.gh

Corresponding author's email:bosomtwemichael@gmail.com ${ }^{1}$

\begin{abstract}
The purpose of this paper was to find out the variance of job satisfaction on four job stressors: management role, role ambiguity, role conflict and workload among registry staff of Takoradi Technical University (TTU) in Ghana. A survey research method was adopted for the study and a questionnaire was used to collect data from 85 registry staff in the University through a convenience sampling technique. A discriminant analysis was used to predict job satisfaction of the registry staff into whether I am satisfied with my job or I don't like my job based on the four job related stressors. The classification model showed that $96.5 \%$ of the sampled registry staff were correctly classified as those who did not like their job or those who were satisfied with their job. The summary of canonical discriminant functions with canonical correlation value of 0.942 suggested the model explained $88.7 \%$ of the variance for the job satisfaction in terms of four job related stressors: management role, work load, role conflict and role ambiguity. Furthermore, role conflict and role ambiguity topped the factors that the registry staff considered as precursors of job dissatisfaction. This research paper used discriminant analysis approach to group job satisfaction levels of registry staff based on four job stressors: management role, role conflict, role ambiguity and workload which would assist the management to minimise job stress in the University.
\end{abstract}

Keywords: Job satisfaction, Job stress, Registry staff, Discriminant Analysis, Takoradi Technical University.

DOI: $10.7176 / \mathrm{JEP} / 11-30-15$

Publication date:October $31^{\text {st }} 2020$

\section{Introduction}

Registry staff of universities are facing work complexities and challenges because of growing number of students' intake, increasing number of private universities presenting competition and changing technologies. These factors have produced many other types of pressures among registry staff. In investigating stress and coping strategies among central administrative staff in University of Ghana, she asserts that $80.8 \%$ of these personnel have some form of job related stress including attending to multiple pressing issues at the same time, working with inadequate resources as well as promoting of staff based on familiarity (Azumah, 2014). Mensah, Fosu and Oteng-Abayie (2017), for example, identify major occupational stress among non-academic staff of public universities in Ghana to include work role ambiguities, inappropriate performance appraisal methods, work load and co-worker relationship issues. Essiam, Mensah, Kudu and Gyamfi (2015) investigated the effect of work load, role ambiguity, physical environment, management and coworker support on job satisfaction in one public university in Ghana. A sample size of 210 teaching staff were selected through a convenience. The finding indicates that the overall effect size of the stressors in the variance of job satisfaction was practically small $[\mathrm{R} 2 \leq .08, \mathrm{~F}(5,210)=4.51, \mathrm{p}=.001]$ and that the job stressors only explained $8 \%$ of the variance in job satisfaction.

This research paper expands on the job stress on job satisfaction of registry staff of Takoradi Technical University (TTU) by examining management role, role conflict, role ambiguity and workload of the registry staff. The 
statistical tool employ in this study is discriminant analysis which will be used to evaluate registry staff views of job stress on job satisfaction. Thus, the job stress consists of management role, role conflict, role ambiguity and workload combined together to predict respondents into two levels of job satisfaction: I am satisfied with my job and I don't like my job. The World Health Organization (WHO) has described job stress as a global epidemic (Avey, Luthans and Jensen, 2009). Job stress is however seen as an alarming issue and at the same time on the increase among university workers as indicated by the world report (Gillespie, Walsh, Winefield, Dua and Stough, 2001).

Most studies on job stress in Ghana have focused in port and harbour, banking sector and other sectors of the economy. In the case of higher education in Ghana, there is the lack of concentrated of research on non-teaching staff (for example, Agyei et al., 2017; Azila-Gbettor,et al., 2014; Essiam, Mensah, Kudu and Gyamfi, 2015; Kusi, Mensah, and Gyaki, 2014). Hence, few studies have been carried on administrative staff in the traditional Ghanaian public universities including Azumah, (2014), Mensah et al. 2017, and Owusu and Tawiah, 2014. For a newly created technical universities, research works on job stress and job satisfaction on administrative staff are nonexistent.

Stress is a problem that exists among workers in general and the supporting staff in the Takoradi Technical University is no exemption. The supporting staff in the university have been employed into various units at the central administration and are faced with heavy workloads, routine and boring jobs. They also provide secretarial services to the departments, offer counselling services, keep records of meetings and allocate rooms for teaching and learning to name but a few. However, the issue of unfair payment systems coupled with low reward system tend to affect their physical and psychological abilities to work effectively to meet expected demands. Ultimately, productivity and turnover of the organisation is affected. The study uses discriminant analysis approach to examine the effect of job stress on job satisfaction of registry staff in Takoradi Technical University.

\section{Literature Review \\ 2.1. Job stress}

Job stress is a global workplace health phenomenon that affects workers of all level. For example, job stress according to Golubic, Milosevic, Knezevic and Mustajbegovic (2009) accounts for about 50 - 60\% of all job related performances. Job stress which is also known as occupational stress describes the effect associated with the negative emotional experiences that workers go through in their line of duty. These negatives emotional experiences that workers feel include frustration to meet deadlines, worrying about job promotion and security all impact on the employees' health and performances.

Work-related stress occurs when there is a mismatch between job descriptions, resources available and employee's capability to perform the task resulting in physical and emotional imbalance. Job stress can be seen in terms of a given task out weighing a workers performance bring about imbalance at the workplace. Stressors are usually associated with interpersonal relationships at work, such as conflicts with the behaviour of supervisors, conflicts with colleagues, conflicts with subordinates and conflicts with management policies. A research report by Winefield and Jarrett (2001) revealed that the employees of Adelaide University experienced high job related stress and low job satisfaction among the teaching staff. Also, a study carried out by Gillespie et al. (2001) among teaching staff and the general staff in the USA, New Zealand, UK and Australia showed that personnel in theses universities had multiples of stress. They identified lack of promotion opportunities, time constraints, high workloads, inadequate recognitions, changing job roles, inadequate salaries, inadequate management or participation in management as the causes of job related stress.

In Ghana, it has been found out in recent time that, individual workers spend longer time working to enable them meet their needs in life and are therefore prone to experiencing stress which comes with some health challenges (Akussah, Dzandu, and Osei-Adu, 2012). According to Akussah et al., (2012) stress among workers contributes to high rate of turnover, absenteeism and work days lost which has cost implications for many organizations. Moreover, performance is also affected by stress, apart from the individual's health. In the case of the University of Ghana, the supporting staff works tirelessly while school is in session, during vacation, reopening of school, admission and registration to accomplish the core function of the university. This can go a long way to cause stress among the supporting staff if measures are not put in place.

\subsection{Job satisfaction}

Job satisfaction describes the feelings that employees receive in their workplaces toward successful completion of a task. Job satisfaction is the overall affection that employees enjoy for achieving a task (Lu, While, and Barriball, 2005). There is growing evidence that current trends in employment conditions may have negative effects on job 
satisfaction and deteriorate the physical and mental health of employees. Affective disposition on job satisfaction consists of two facets: positive affectivity and negative affectivity. High energy, eagerness, and pleasurable involvement represent positive affectivity while distress, unpleasant involvement, and nervousness show negative affectivity (Judge and Larsen, 2001). It can be considered as a sense of achieved related a given task and the desire to raise productivity in the organisation. Thus, job satisfaction is the affective orientation that an employee has towards his or her work.

\subsection{Management Role as a Source of Job stress}

The role that management plays in the organisation can cause job stress as management assigns roles and duties to their subordinates Management most often implements the decision of the board through determining who should work in a certain capacity and the require logistics provision to accomplish the given task. Workers in an organisation can face occupational stress through the role stress that the management serves. Role stress means anything in the organisation that produces job stress for the subordinates in executing the given task. Management role of an organisation is one of the aspects that affect work-related stress among workers. Role related stress is concerned with how individuals perceive the expectations others have of them which includes role ambiguity and role conflict (Alexandros-Stamatios, Matilyn and Cary, 2003).

\subsection{Workloads as a Source of Job stress}

Several studies have highlighted the deleterious consequences of high workloads or work overload. Humboldt, Leal, Laneiro and Tavares (2013) conducted a study among 39 management consultants on the occupational stress, sources of stress and stress management strategies through the eyes of management consultants using a multiple correspondence analysis for latent constructs. They reported a high workload of $15.1 \%$ among management consultants on their job related stress in their organisation.

Workload stress is the feeling of constant pressure and reluctance to go to work accompanied by the general mental, emotional and behavioural stress experienced by the worker. In the view of Al-Aameri (2003), one of the job related stresses identified in his research study is pressure originating from workload. In other study, VinokurKaplan (1991) stated that organisation factors such as workload and working condition were negatively related with job satisfaction. A study in UK indicated that the majority of the workers were unhappy with the current culture where they were required to work extended hours and cope with large workloads while simultaneously meeting production targets and deadlines (Townley, 2000).

\subsection{Role ambiguity as a Source of Job stress}

Role ambiguity is another aspect that affects job stress in the workplace. Role ambiguity exists when an individual lacks information about the requirements of his or her role, how those role requirements are to be met, and the evaluative procedures available to ensure that the role is being performed successfully (Cordes \& Dougherty, 1993; Dyer \& Quine, 1998). According to Muchinsky (1997), role ambiguity can lead to low job performance resulting in low self-confidence, worrying and anxiety.

\section{Methodology 3.1 Research design and data collection}

A survey research design was adopted for the study during the 2019/2020 academic year. A sample size of 85 registry staff of Takoradi Technical University were surveyed using convenience sampling method. Subsequently, a self-administered structured survey questionnaire was used to collect primary data from the registry staff. The respondents of this study were assured of privacy of information and a discriminant analysis was used to classify the responses of registry staff into whether I am satisfied with my job or I don't like my job. The analytical tool used in this study was IBM SPSS Version 20.

\subsection{Instrument Development}

The instrument used in this study composed of personal information of the respondents and the effect of job stress and job satisfaction. The personal data consist of demographic questions such as gender, age, marital status and education level of the registry staff of Takoradi Technical University. Caplan, Cobb, French, Harrison, and Pinneau's (1975) job stress questionnaire was modified to suit the current study. This scale included four dimensions from Caplan et al (1975), namely (1) workload, (2) role conflict, (3) role ambiguity and (4) performance pressure which comprised thirteen items. However, performance pressure was modified to 
management role to cover for relationship concern in the University. Each of job stressors was measured on a sixpoint Likert Scale in which 1 indicated "strongly disagree", 2 indicated "disagree", 3 indicated "somewhat disagree", 4 indicated "somewhat agree", 5 indicated "agree" and 6 indicated "strongly agree".

\section{Data analysis procedures}

A discriminant analysis approach is an analytical technique that can be used to classify the responses into groups based on their distinct characteristics. In this research study, a discriminant analysis was conducted to see whether the four predictor variables on job stress (management role, role conflict, work load and role ambiguity) could predict job satisfaction (I am satisfied with my job and I don't like my job) of the registry staff of Takoradi Technical University in Ghana.

Prior to conducting discriminant analysis using SPSS version 20, the researchers performed a collinearity check to see that no perfect linearity exists among the predictor variables. The multicollinerarity test showed that the tolerance values were greater than 0.1 (Menard, 1995) and VIF (variance inflation factors) values were less than 10 (Myer, 1990) indicating the acceptance level for discriminant analysis as shown in Table 1.

Table1: Coefficients of multicollinerarity assessment

\begin{tabular}{|c|c|c|c|c|c|c|}
\hline \multirow{2}{*}{$\begin{array}{l}\text { Model } \\
1\end{array}$} & \multicolumn{2}{|c|}{ Unstandardized Coefficients } & \multirow[t]{2}{*}{$\mathrm{t}$} & \multirow[t]{2}{*}{ Sig. } & \multicolumn{2}{|c|}{ Collinearity Statistics } \\
\hline & B & Std. Error & & & Tolerance & VIF \\
\hline (Constant) & -.341 & .050 & -6.820 & .000 & & \\
\hline Management role & .078 & .014 & 5.546 & .000 & .533 & 1.878 \\
\hline Work load & -.062 & .019 & -3.247 & .002 & .286 & 3.493 \\
\hline Role conflict & .125 & .026 & 4.808 & .000 & .128 & 7.799 \\
\hline Role ambiguity & .119 & .029 & 4.110 & .000 & .116 & 8.656 \\
\hline
\end{tabular}

Survey data, 2020.

According to Table 2, the analysis of the group statistics for mean and standard deviation scores for management role, work load, role conflict and role ambiguity and job satisfaction levels were computed. The mean values show a discrimination between I am satisfied with my job and I don't like my job for the four independent variables: management role, work load, role conflict and role ambiguity. For example, I don't like my job recorded high mean values (management role: $M=4.91$; work load: $M=4.84$; role conflict: $M=4.96$; and role ambiguity: $M=5.02$ ) indicating a discrimination between I am satisfied with my job recorded low mean values (management role: $\mathrm{M}=2.54$; work load: $\mathrm{M}=2.25$; role conflict: $\mathrm{M}=1.32$; and role ambiguity: $\mathrm{M}=1.61$ ) for the respondents. The findings of the study is line with Essiam et al. (2015) that the overall effect size of work load, role ambiguity, physical environment, management and coworker support in the variance of job satisfaction was practically small and that the job stressors only explained $8 \%$ of the variance in job satisfaction.

A study of Table 3 shows that there is group means differences across the registry staff population for I am satisfied with my job and I don't like my job in terms of the four variables: management role, work load, role conflict and role ambiguity. Thus, the significant value of 0.000 indicates that the test null hypothesis of population covariance matrices should be reject. Also, one function was generated and was significant $[\Lambda=.112, \chi 2(4, \mathrm{~N}=85)=177.252$, $\mathrm{p}<.000]$ indicating that the function of predictors significantly differentiated between job satisfaction being classified as I am satisfied with my job and I don't like my job. The findings of the study agree with Mensah, et al.'s (2017) study that registry staff of public universities in Ghana face job related stress such as work role ambiguities, inappropriate performance appraisal methods or management roles, work overload and co-worker relationship issues thereby affecting their job satisfaction level. 
Table 2: Group statistics of mean and standard deviation on job stress and job satisfaction Job Satisfaction Mean Std. Deviation Valid N (listwise)

\begin{tabular}{|c|c|c|c|c|c|}
\hline & & & & Unweighted & Weighted \\
\hline \multirow{4}{*}{ I am satisfied with my job } & Management role & 2.54 & 1.644 & 28 & 28.000 \\
\hline & Work load & 2.25 & 1.531 & 28 & 28.000 \\
\hline & Role conflict & 1.32 & .476 & 28 & 28.000 \\
\hline & Role ambiguity & 1.61 & .567 & 28 & 28.000 \\
\hline \multirow{4}{*}{ I don't like my job } & Management role & 4.91 & 1.106 & 57 & 57.000 \\
\hline & Work load & 4.84 & 1.049 & 57 & 57.000 \\
\hline & Role conflict & 4.96 & .925 & 57 & 57.000 \\
\hline & Role ambiguity & 5.02 & .876 & 57 & 57.000 \\
\hline \multirow{4}{*}{ Total } & Management role & 4.13 & 1.717 & 85 & 85.000 \\
\hline & Work load & 3.99 & 1.729 & 85 & 85.000 \\
\hline & Role conflict & 3.76 & 1.900 & 85 & 85.000 \\
\hline & Role ambiguity & 3.89 & 1.793 & 85 & 85.000 \\
\hline
\end{tabular}

Survey data, 2020. 
Table 3: Box's Test of Equality of Covariance Matrices

\begin{tabular}{llr}
\hline Box's M & & $\mathbf{7 5 . 8 6 0}$ \\
F & Approx. & 7.115 \\
& df1 & 10 \\
& df2 & 13874.806 \\
& Sig. & .000 \\
\hline
\end{tabular}

Tests null hypothesis of equal population covariance matrices.

As shown in Table 4, the Wilks' Lambda value of 0.112 which is close 0.0 value indicates a strong difference between job satisfaction in terms of management role, work load, role conflict and role ambiguity among the registry staff. The finding of the study is support Essiam et al's (2015) work that work load, role ambiguity, physical environment, management and coworker support in the variance of job satisfaction was practically small and that the job stressors only explained $8 \%$ of the variance in job satisfaction.

Table 4: Wilks' Lambda

\begin{tabular}{lllll}
\hline Test of Function(s) & Wilks' Lambda & Chi-square & df & Sig. \\
$\mathbf{1}$ & .112 & 177.252 & 4 & .000 \\
\hline
\end{tabular}

Survey data, 2020.

Table 5 presents the summary of canonical discriminant functions with canonical correlation value of 0.942 suggests the model explains $88.7 \%$ of the variance for the job satisfaction in terms of four job related stressors: management role, work load, role conflict and role ambiguity. The finding of the study is support Essiam et al's (2015) work that work load, role ambiguity, physical environment, management and coworker support in the variance of job satisfaction was practically small and that the job stressors only explained $8 \%$ of the variance in job satisfaction.

Table 5: Summary of Canonical Discriminant Functions

\begin{tabular}{lcccc}
\hline Function & Eigenvalue & \% of Variance & Cumulative \% & Canonical Correlation \\
$\mathbf{1}$ & $7.920^{\mathrm{a}}$ & 100.0 & 100.0 & .942 \\
\hline
\end{tabular}

a. First 1 canonical discriminant functions were used in the analysis.

Table 6 presents the standardized function coefficients which indicate that management role, work load, role conflict and role ambiguity test contribute to discriminating job satisfaction among registry staff in Takoradi Technical University. The order of importance in predicting group membership among the four predictors indicated the management role, role conflict, role ambiguity and workload followed in the order importance in predicting job satisfaction among registry staff in Takoradi Technical University. These factors have produced many other types of pressures among registry staff. The findings support research report by Winefield and Jarrett (2001) revealed that the employees of Adelaide University experienced high job related stress and low job satisfaction among the teaching staff. 
Table 6: Standardized Canonical Discriminant Function Coefficients and Structure Matrix

\begin{tabular}{lll}
\hline Items & \multicolumn{1}{l}{$\begin{array}{l}\text { Standardized Canonical Discriminant } \\
\text { Function Coefficients }\end{array}$} & Structure Matrix \\
\cline { 2 - 3 } & Function 1 & Function 1 \\
\hline Management role & .682 & .308 \\
Work load & -.508 & .357 \\
Role conflict & .672 & .763 \\
Role ambiguity & .628 & .731
\end{tabular}

Pooled within-groups correlations between discriminating variables and standardized canonical discriminant functions. Variables ordered by absolute size of correlation within function.

The data in Table 7 provides information on the percentage of cases original classify into I am satisfied with the job or I don't like my job. The classification results show that the model correctly predicts $96.5 \%$ registry staff into those who like their job or those who don't like their job and $95.3 \%$ of cross-validated grouped cases correctly classified. From the table, the registry staff who don't like their job were better classified (94.7\%) than those who were satisfied with their job $(100 \%)$.

Table 7: Classification Results ${ }^{a, c}$

\begin{tabular}{|c|c|c|c|c|c|}
\hline & & \multirow[t]{2}{*}{ Job Satisfaction } & \multicolumn{2}{|c|}{ Predicted Group Membership } & \multirow[t]{2}{*}{ Total } \\
\hline & & & $\begin{array}{l}\text { I am satisfied } \\
\text { with my job }\end{array}$ & $\begin{array}{l}\text { I don't like my } \\
\text { job }\end{array}$ & \\
\hline \multirow[t]{4}{*}{ Original } & Count & $\begin{array}{l}\text { I am satisfied with my } \\
\text { job }\end{array}$ & 28 & 0 & 28 \\
\hline & & I don't like my job & 3 & 54 & 57 \\
\hline & $\%$ & $\begin{array}{l}\text { I am satisfied with my } \\
\text { job }\end{array}$ & 100.0 & .0 & 100.0 \\
\hline & & I don't like my job & 5.3 & 94.7 & 100.0 \\
\hline \multirow[t]{4}{*}{$\begin{array}{l}\text { Cross- } \\
\text { validated }^{b}\end{array}$} & Count & $\begin{array}{l}\text { I am satisfied with my } \\
\text { job }\end{array}$ & 28 & 0 & 28 \\
\hline & & I don't like my job & 4 & 53 & 57 \\
\hline & $\%$ & $\begin{array}{l}\text { I am satisfied with my } \\
\text { job }\end{array}$ & 100.0 & .0 & 100.0 \\
\hline & & I don't like my job & 7.0 & 93.0 & 100.0 \\
\hline
\end{tabular}

a.96.5\% of original grouped cases correctly classified. b. Cross validation is done only for those cases in the analysis. In cross validation, each case is classified by the functions derived from all cases other than that case. c. $95.3 \%$ of cross-validated grouped cases correctly classified. 


\section{Conclusions and Recommendations}

It can be concluded from the findings of the study that job satisfaction differences among the registry staff on job stresses vary in terms of management role, work load, role conflict and role ambiguity. Therefore, the study found that management role, role conflict and role ambiguity largely predicted job satisfaction of the registry staff. Furthermore, role conflict and role ambiguity issues affecting job satisfaction could be enhanced when job description and analysis practices are encouraged. It was suggested that the university management should support the staff in collegiate relationship, logistics and peer support to enhance job satisfaction.

\section{Research limitations/implications}

The study of this natural has several limitations. For instance, the use of one technical university in Ghana poses a limitation to the study because the findings cannot be extended beyond the institution under study. The study also employed non-probability sampling in the selection of participants which might the generalisation of the findings of the study. Thus, applying the findings of the study beyond of the study should be done with cautions. However, every effort was put in place to ensure reliability and validity of the study results. It was suggested that the university management should support the staff in collegiate relationship, logistics and peer support to enhance job satisfaction.

\section{ACKNOWLEDGEMENTS}

We would like to express my profound gratitude to God Almighty who helped us to put this piece together. We also wish to acknowledge the support of Vice Chancellor of Takoradi Technical University and the Management. We appreciate the efforts of all the Administrative staff of the University for their openness in responding positively to the questionnaire.

\section{References}

Agyei, D. D., Kpeglo, S., Agyen, J. K., Yankey, F. W. M., Osei-Yeboah, J., Agboli, E., ... and Owusu-Mensah, R. (2017). "Occupational Psychosocial Stress among Staff of the University of Health and Allied Sciences, Ho, Ghana”. Journal of Education, Society and Behavioural Science, 1-10.

Akussah, H., Dzandu, M. D., and Osei-Adu, M. (2012). "Stress and coping mechanisms among workers of the Public Records and Archives Administration Department (PRAAD) Headquarters, in Ghana". Mousaion, 30(1), $1-18$.

Al-Aameri A.S., (2003). "Source of job stress for nurses in public hospitals", Saudi Medical Journal, 24(11), pp.1183-1187.

Alexandros-Stamatios, G.A., Matilyn, J.D. and Cary, L.C., (2003) "Occupational stress, job satisfaction, and health state in male and female junior hospital doctors in Greece". Journal of Managerial Psychology, Vol. 18, No. 6, pp. 592-621.

Avey, J. B., Luthans, F., and Jensen, S. M. (2009). Psychological capital: A positive resource for combating employee stress and turnover. Human Resource Management, 48(5), 677-693

Azila-Gbettor, E. M., Atatsi, E. A., Dodor, C. T., Clarkson, T., Adade, D. K. T., and Neequaye, K. (2017). "Work Stress and Performance of Faculty Members of a Ghanaian Technical University". International Journal of Research in Business Studies and Management. Vol. 4, Issue 10, pp. 38-49.

Azumah, Y. A. (2014). "Stress and Coping Strategies among Supporting Staff at the Central Administration in the University of Ghana". Master's dissertation, University of Ghana.

Caplan, R. D., Cobb, S., French, J. R., Harrison, R. V., and Pinneau, S. R. (1975). "Job demands and worker health". HEW Publication No. (NIOSH), pp. 75-160.

Cordes, C.L. and Dougherty, T.W., (1993). “A review and an integration of research on job burnout". Academy of management review, 18(4), pp.621-656. 
Dyer, S. and Quine, L., (1998). "Predictors of job satisfaction and burnout among the direct care staff of a community learning disability service". Journal of Applied Research in Intellectual Disabilities, 11(4), pp.320332.

Essiam, J. O., Mensah, M. E., Kudu, L. K., and Gyamfi, G. D. (2015). "Influence of job stress on job satisfaction among university staff: Analytical evidence from a public university in Ghana". International Journal of Economics, Commerce and Management, 3(2), 1-15.

Gillespie, N. A., Walsh, M., Winefield, A. H., Dua, J., and Stough, C. (2001). “Occupational stress in universities: staff perceptions of the causes, consequences and moderators of stress". Work and Stress, 15(1), 53-72.

Golubic, R., Milosevic, M., Knezevic, B., and Mustajbegovic, J. (2009). "Work-related stress, education and work ability among hospital nurses". Journal of advanced nursing, 65(10), 2056-2066.

Humboldt, S., Leal, I., Laneiro, T. and Tavares, P., (2013). "Examining occupational stress, sources of stress and stress management strategies through the eyes of management consultants: A multiple correspondence analysis for latent constructs". Stress and Health, 29(5)

Kusi, H., Mensah, D. K. D., and Gyaki, E. (2014). "Work related stress among the academic staff of the University of Education, Winneba campus, Ghana". Journal of Education and Practice, 5(13), 15-23.

Love, K. M., Tatman, A. W., and Chapman, B. P. (2010). "Role stress, interrole conflict, and job satisfaction among university employees: the creation and test of a model". Journal of employment counseling, 47(1), 30-37.

Menard, S. (1995). "Applied Logistic Regression Analysis: Sage University Series on Quantitative Applications in the Social Sciences", Thousand Oaks, CA: Sage.

Mensah, H. K., Fosu, F. A., and Oteng-Abayie, E. F. (2017). "Occupational stressors among university nonacademic staff: results from a representative public university in Ghana". International Journal of Business Excellence, 13(2), 200-216.

Muchinsky, P.M., (1997). 'Stress and well-being at work: Psychology applied to work'. Pacific Grove, CA: Brooks/Cole.

Myers, R.H., (1990). “Classical and modern regression with applications.” (Vol. 2). Belmont, CA: Duxbury press.

Owusu, G. A, and Tawiah, M. A., (2014). "Stress management among senior staff female administrators in the University of Cape Coast”. Int. J. Acad. Res. Progress. Educ. Dev. 3(4):78-100.

Rehman, M., Irum, R., Tahir, N., Ijaz, Z., Noor, U., and Salma, U. (2012). "The impact of job stress on employee job satisfaction: A study on private colleges of Pakistan”. Journal of Business Studies Quarterly, 3(3), 50.

Townley, G. (2000). “Long hours culture causing economy to suffer”, Management Accounting, 78 (6), pp.3-5.

Vinokur-Kaplan J.X. (1991). "Job Satisfaction among Social Workers in Public and Voluntary Child Welfare Agencies”, Child Welfare, 155, pp. 81-91.

Winefield, A.H. and Jarrett, R., (2001). "Occupational stress in university staff”. International journal of stress management, 8(4), pp.285-298 